\title{
A new corrected proof sheet from Shakespeare's First Folio (1623)
}

Five corrected proof sheets from Shakespeare's First Folio (1623) have previously been identified. A copy in the Huntington Library has a corrected proof sheet from King Lear (sig. $\left.r r 3^{1}\right){ }^{1}$ Three copies in the Folger Shakespeare Library have corrected proof sheets: from Lear (Folger 48, sig. qq6 $6^{\mathrm{r}}$; from Romeo and Juliet (Folger 50, sig. ff6 ${ }^{\mathrm{r}}$; ${ }^{3}$ and from Othello (Folger 46, sig vv3'). A fifth proof sheet, from Antony and Cleopatra sig. xx6 ${ }^{\mathrm{v}}$, exists as a fragment collected by J. O Halliwell-Phillipps and now at the Folger. ${ }^{4}$ It is now possible to describe a previously unnoticed sixth. This proof sheet, of King Lear (sig. rr2 ), is bound in a copy that once belonged to David Garrick and is now in the library of The Queen's College Oxford (fig. 1).

Four pages of quire rr were corrected. Charlton Hinman estimated that these four were the only ones of the quire set by Compositor E, although subsequent studies have been less convinced about the absolute connection between spelling preferences and contributor distribution that was so important to Hinman's account. ${ }^{5}$ The Huntington Library copy preserves one of the other corrected sheets from King Lear, making this the only quire for which we have more than one proof sheet extant. The proof-reading

\footnotetext{
${ }^{1}$ James G. McManaway, 'Another Discovery of a Proof Sheet in Shakespeare's First Folio', Huntington Library Quarterly 41 (1977), pp. 19-26.

${ }^{2}$ Charlton Hinman, 'Mark III: New Light on the Proof-Reading for the First Folio of Shakespeare', Studies in Bibliography 3 (1950/1951), pp.145-153

${ }^{3}$ Charlton Hinman, 'A Proof-sheet in the First Folio of Shakespeare', The Library 23 (1942), pp.101-7.

${ }^{4}$ Charlton Hinman, The Printing and Proof-Reading of the First Folio of Shakespeare vol 1 (Oxford: Clarendon Press, 1963), pp. 317-8.

${ }^{5}$ Charlton Hinman, ed., The Norton Facsimile: The First Folio of Shakespeare, second edition with a new introduction by Peter W.M. Blayney (W.W. Norton and Company: New York and London, 1996), xxxvii. For a sceptical revision of Hinman's assumptions about spelling, see Pervez Rizvi, 'The Use of Spellings for Compositor Attribution in the First Folio', PBSA 110:1 (2016) pp. 1-54.
} 
symbols are recognisable from other proof sheets. The handwriting is not obviously different from the style on the other sheets, and therefore does not provide any definitive evidence on the question of whether a single reader undertook all the proof reading (sometimes speculated to have been Isaac Jaggard). What does seem distinctive about this proof sheet compared to the others is the consistency of the ink. The other proof sheets show smooth, mid-brown pen strokes (notwithstanding that the leaves of the Huntington copy have been washed); the ink on $\mathrm{rr} 2^{\mathrm{r}}$ seems greasier and more clotted than these other examples, as the page, and the mark-through on the verso, reveal. For example, the mark indicating the mistaken ' $s$ ' in 'mads' (TLN 1586) is a heavy blotch surrounded by a larger ring of pale red-brown around the pen strokes: this greasy separation does not appear in other proof sheets.

There are nine corrections marked on the proof sheet for $r r 2^{r}$. As in all the other extant proof sheets, the corrections mark obvious mechanical errors and show no evidence of being read against copy. The reader has marked the turned letter in 'wheu' (TLN 1522), the words run together as 'anddanger' (TLN 1535), the error 'Nattue' for 'Nature' (TLN 1566), the missing $r$ in 'daughte s' (TLN 1574) and the rogue comma in 'Ile, weepe' (TLN 1596), all registered as variants in Hinman's collation. The corrected proof sheet makes clear that the proof-reader did indeed 'correct' 'hot-blooded France' to 'hotbloodied France', using an insertion mark in the text and an ' $i$ ' just visible in the gutter. Hinman wrote that we cannot 'readily account for such a change except as a mistake on the part of the Folio reader'. ${ }^{6}$ Most modern editions including the Oxford, Cambridge, Folger and Norton do indeed prefer the uncorrected reading, but it may be worth noting that there is another Folio instance of 'hot-bloodied', in The Merry Wives of Windsor (TLN 2483), and no example anywhere in the text of the now-standard 'hot-blooded'.

\footnotetext{
${ }^{6}$ Hinman (1963), vol 1. p.309.
} 
The processes of correction have, as usual, sometimes introduced errors themselves. The instruction to insert a space in 'trueneed' (TLN 1570) has resulted in a medial line rather than white space between the words, showing a partially-inking raised space. At TLN 1586 'mads' is corrected, but corrected sheets also show that the necessary extra space was imperfectly pushed down after 'mad.', registering as an inked block. The correction at TLN 1509, to close up a space in 'sump ter', has not been made in corrected copies, hence Hinman's count of eight variants on this page. According to Eric Rasmussen and Anthony James West's catalogue, 32 First Folios exist with $\mathrm{rr}^{\mathrm{r}}$ in its uncorrected state, approximately $13.7 \%$ of the extant total. ${ }^{7}$ Perhaps coincidentally, this echoes Hinman's calculation of the proportion of uncorrected Romeo and Juliet leaves, based on a much smaller sample of First Folio copies accessible to him in the wartime Folger Library. ${ }^{8}$

The Queen's College copy which includes this proof sheet belonged to David Garrick and was purchased on his death in 1823 by Thomas Jolley. Bookplates of both men are pasted in the volume. It was apparently rebound in red goatskin in the first half of the nineteenth century by Clark and Bedford, whose stamp is found on the end-paper, dating the rebinding to the period of their partnership of 1841-50. Since the book changed hands twice during that period either owner might have commissioned the new binding. At Jolley's death in 1843 the book was described as 'a fine and perfect copy, free from worm or stain, with the exception of the lines by Ben Jonson, which are supplied by a fac-simile by Mr Harris. If it is possible for any thing to advance the value of this book, it is, that of its having formerly belonged to one of his best commentators, David

\footnotetext{
${ }^{7}$ Eric Rasmussen and Anthony James West (eds), The Shakespeare First Folios: A Descriptive Catalogue (Palgrave Macmillan: Basingstoke, 2012). The West numbers of the volumes with uncorrected $\operatorname{rr} 2^{\mathrm{r}}$ are: $6,9,10,15,23,25,27,33,35,37,54,57,59,64,70,76,79$, 105, 106, 112, 125, 134, 154, 165, 174, 183, 186, 190, 195, 198, 217, 231.

${ }^{8}$ Hinman (1950/51), p. 66.
} 
Garrick'. It was bought by the bookseller Thomas Rodd, and thence passed to Queen's College around 1850. The volume has few obvious marks of use beyond a handful of marginal pencil crosses, and the manuscript addition of a missing speech prefix 'Orl' in As You Like It. But in addition to its celebrity provenance, this copy of the First Folio has an additional claim on our attention as it can now be acknowledged to preserve a sixth corrected proof sheet.

${ }^{9}$ Catalogue of the Fourth Portion of the extensive, singularly curious and valuable library of Thomas Jolley, Esq, FSA (Sotheby, 1844), p.46. 